\title{
Big data, satellites and climate change
}

Last update: 9 March 2017

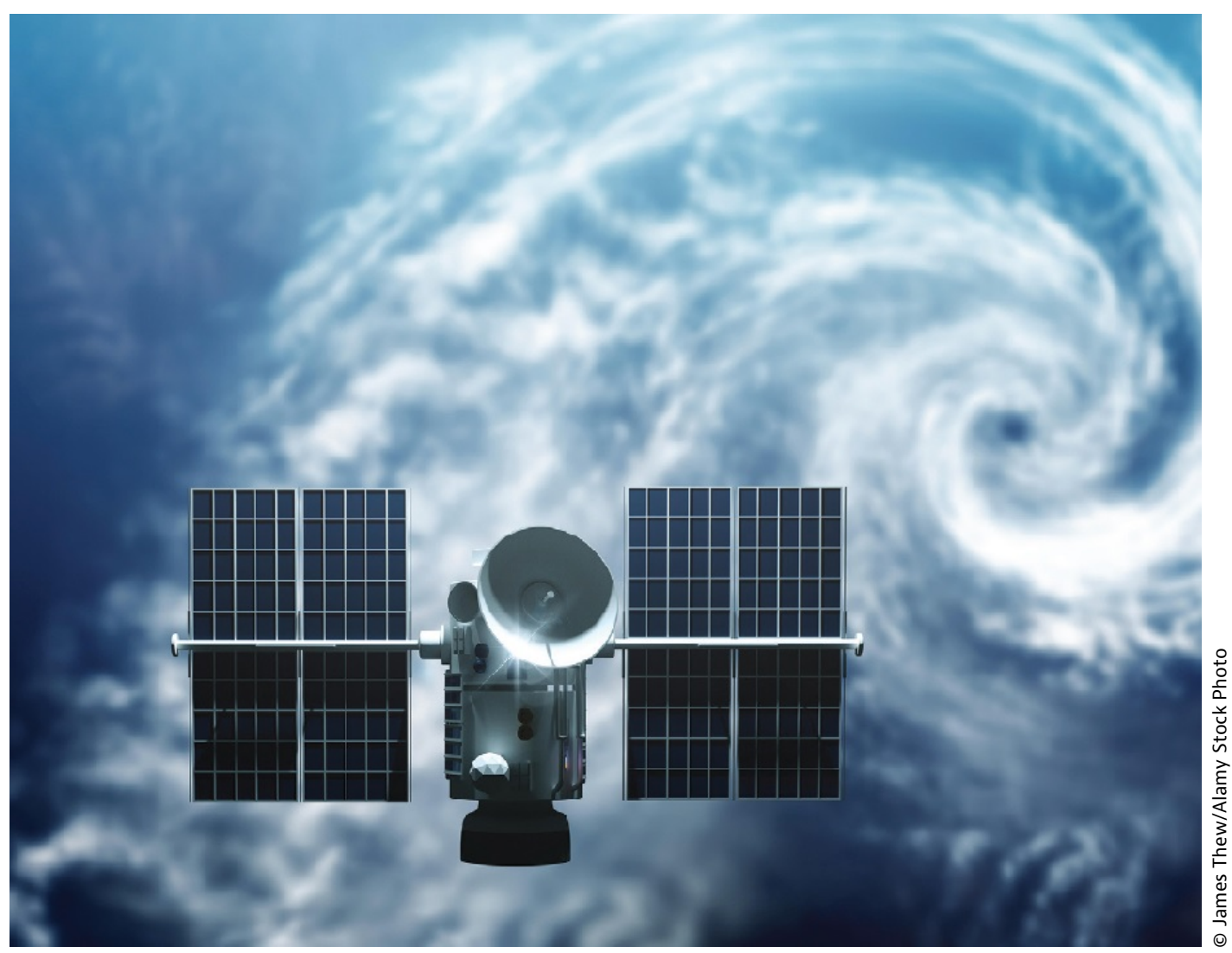

Meteorology was the first scientific discipline to use space capabilities in the 1960s, and today satellites provide observations of the state of the atmosphere and ocean surface for the preparation of weather analyses, forecasts, advisories and warnings, for climate monitoring and environmental activities. Three-quarters of the data used in numerical weather prediction models depend on satellite measurements.

International co-ordination for climate monitoring is led by the Steering Committee of the Global Climate Observing System (GCOS). This group was created in 1992 by the World Meteorological Organization, the Intergovernmental Oceanographic Commission, UNESCO and the United Nations Environment Programme. Noting that climate change was at this time still poorly understood and documented in many countries, the GCOS championed the introduction of a 
range of "essential climate variables" or ECVs-physical, chemical or biological variables or a group of linked variables that critically contributes to the characterisation of earth's climate-to more comprehensively and systematically monitor changes to the climate, in this way supporting the work of the Intergovernmental Panel on Climate Change (IPCC).

Earth observation satellites are firmly embedded in this international system to monitor climate change. Satellite data provide significant contributions to more than half of the 50 essential climate variables that are currently in use. Some of these contributions can only be provided by satellite. This includes satellite radar altimetry, which measures the distance between the spacecraft and the earth's surface below and can provide precise and continuous measures of global sea levels. Groundwater storage, recharge and discharge can be measured by changes and variations in earth gravity, which, in turn are detected by satellites.

[...]Satellite instruments are also responsible for measuring the chemical composition of the atmosphere and tracking the presence of carbon dioxide, methane, ozone and other greenhouse gases; the monitoring of sea ice, polar ice caps, ice sheets and glaciers (using altimetry, radar imagery and gravitational instruments); and finally, the monitoring of extreme weather events through the observation of sea surface temperatures, wind speed and sea levels, and tracking storms via powerful optical satellites in geostationary orbit.

With new-generation satellites, both optical and temporal resolutions will be greatly improved, which will also lead to improved weather forecasting and climate modelling abilities, as well as better real-time monitoring of many

With new-generation satellites, both optical and temporal resolutions will be greatly improved variables in the next decade. Improved satellite instruments will allow a broader range of measurements, as new-generation satellites replace and supplement existing missions. Several new missions will be launched within the next five years, including Eumetsat's second-generation polar-orbiting satellites and thirdgeneration geostationary Meteosats and the European Sentinels in the Copernicus programme, as well as several Chinese satellites. Secondly, coverage and system resilience will be improved thanks to better international co-operation and more national providers and co-operative international missions. For instance, the Chinese FY-3 satellites will be the third pillar in the constellation of polar-orbiting systems, in addition to US and European satellites, according to the World Meteorological Organization.

Approximately 130 earth observation missions were operational as of October 2015, according to the database of the Committee for Earth Observation Satellites, which is a co-ordination body for earth observation satellite activities, originally established by the G7 countries in 1984. This includes missions and/or instruments to observe the atmosphere, land, oceans, ice and snow, as well as gravity and magnetic fields, and as such comprising weather satellites and many 
remote sensing satellites, operated by government agencies, thus excluding commercial constellations such as Skybox, GeoEye, WorldView, etc., which may appear in other databases for remote sensing. Some of these missions are dualuse (such as Italy's CosmoSkyMED constellation), meaning that some of the instruments may also have commercial or military applications.

Many missions are also the result of international co-operation, with several agencies contributing instruments or other types of support. A satellite mission consists of one or several satellites (the GRACE mission, for instance, consists of two satellites flying in formation), carrying one or several instruments. About 350 instruments are currently flown on missions supported by the CEOS. The majority of missions are operated by the United States, Europe (including the ESA, Eumetsat and national agencies), China and the Russian Federation. Future missions are in different stages of preparation and financial approval. So far, 66 missions have been approved to replace or supplement existing activities within the next 15 years, while another 100 are more uncertain, either planned or under consideration, some of which may eventually be abandoned.

Innovation is progressing but continuity of observations remains a concern. Government programme cuts, satellite failures and delays pose a constant threat to measurement systems. Indeed, gaps in the time series of meteorological data were mentioned in the US Government Accountability Office's high-risk report for 2015. The Steering Committee of the Global Climate Observing System reports that measurements of certain essential climate variables (solar irradiance and of sea-surface temperature at microwave frequencies) are at risk of being discontinued.

Storage and long-term preservation of data is also an issue. With increased optical and temporal resolution, satellite missions produce an increasing amount of data. [...]It may become more difficult to decide which data to archive for long-term conservation and which to use for further processing and then discard. [...] 


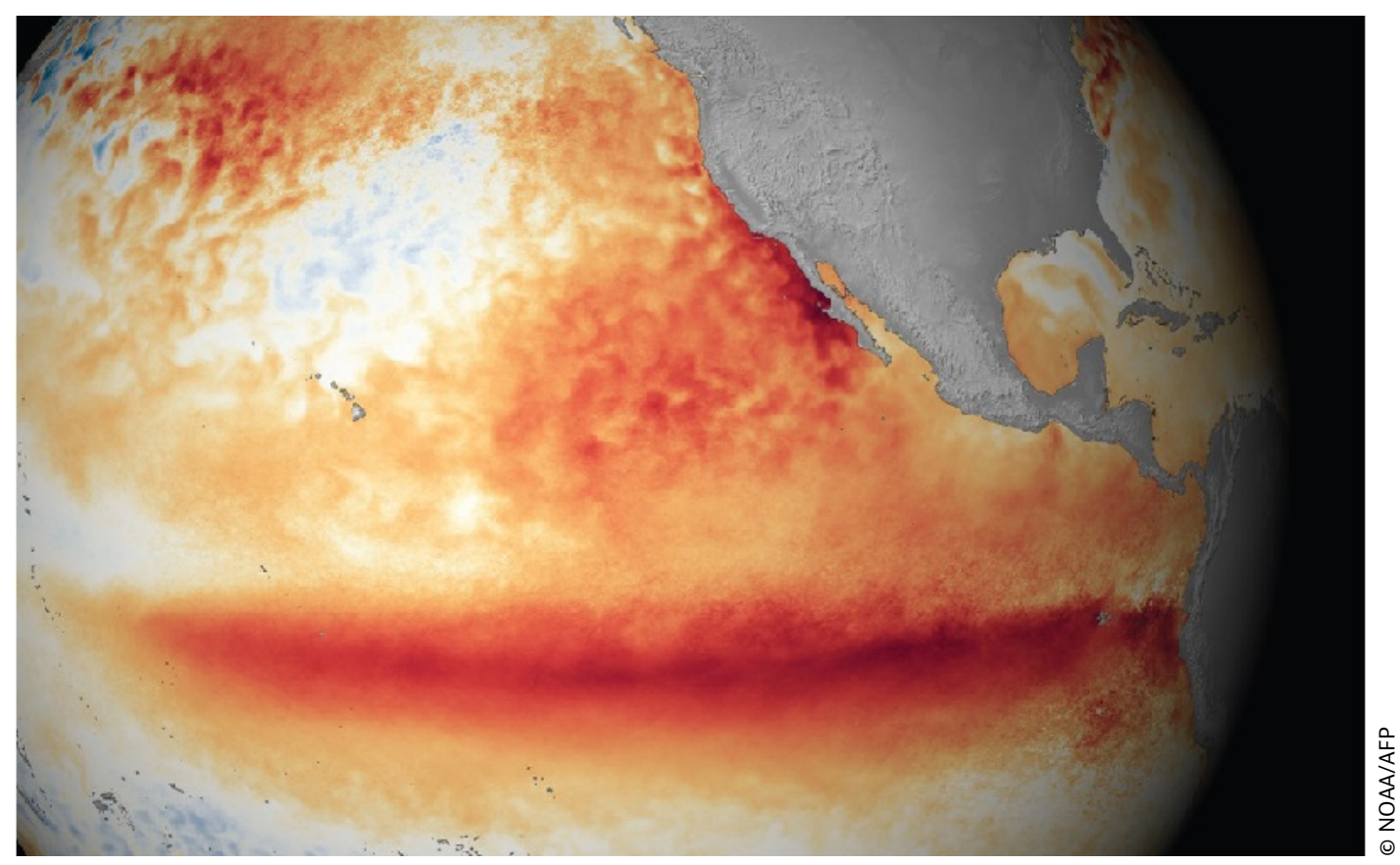

This raises the issue of data access and distribution. To maximise the societal benefits of the data, data need to be efficiently shared and distributed, and raw data must be transformed into value-added products.[...] There are discussions in the community on how the development of commercial downstream services could affect data accessibility policies in the long run. Public-private partnerships are one of the available options to pool costs and reduce government spending on satellite missions and on long-term data storage. However, this could have a negative impact on data sharing and accessibility.

Extracted and adapted from "Could big data from satellites play a major role in climate change management?" in Chapter 4 of Space and Innovation, OECD Publishing, 2016

\section{Contact Claire.Jolly@oecd.org}

\section{References}

Space and Innovation http://dx.doi.org/10.1787/9789264264014-en

The Space Economy at a Glance 2014 http://dx.doi.org/10.1787/9789264217294en

US Government Accountability Office (2015), "High-risk series: An update", GAO-15-290, Government Accountability Office, Washington, DC http:// www.gao.gov/assets/670/668415.pdf

World Meteorological Organization (2015), "Status of the Global Observing System for Climate: Full report", GCOS-195, World Meteorological Organization, Geneva, October http://www.wmo.int/pages/prog/gcos/Publications/

GCOS-195_en.pdf 